\title{
Estudo radiométrico da Praia dos Namorados em Anchieta-ES
}

\author{
Ferreira, B.C.S ${ }^{1}$,Braga, H. M ${ }^{1}$; Passamai, Jr.J.L. ${ }^{2 *}$; \\ 1 Departamento de Química e Física, Universidade Federal do Espírito Santo, Alegre, ES, Brasil. \\ 2 Departamento de Física, Universidade Federal do Espirito Santo, Vitória, ES, Brasil.
}

*e-mail:passamaijr@gmail.com

\section{Resumo}

O objetivo do nosso trabalho foi investigar através de uma determinada rota a atividade radioativa na areia Praia dos Namorados utilizada pelos banhistas, na cidade de Anchieta-ES utilizando uma metodologia dinâmica (variação com tempo). As medidas foram tomadas em tempos distintos durante o período de (agosto de 2016 a abril de 2017). Para tanto um ciclocomputador Etrex-10 foi usado para determinar uma rota na areia da praia usada por banhistas e também um contador Geiger que mediu e armazenou os dados.

\section{Abstract}

The objective of our work was to investigate, through a certain route, the radioactive activity in the Praia dos Namorados sand used by bathers in the city of Anchieta-ES using a dynamic methodology (variation with time). Measures were taken at different times during the period from (August 2016 to April 2017). An Etrex-10 cyclocomputer was used to determine a route in the beach sand used by bathers and also a Geiger counter that measured and stored the data.

\section{Introdução}

Trabalho anterior de Orlando et al. [1] relata a possível relação da atividade radioativa nas praias de Guarapari com efeitos biológicos. Indiferente ao efeito da radiatividade, verificase que em geral os autores, anteriores a este estudo, descrevem as propriedades das areias utilizando amostras retiradas em um único local, de forma singular no tempo $[2,3,4]$. Esses trabalhos tiram correlações sobre uma amostra singular e com uma composição não reprodutível no tempo.

Neste trabalho foi realizada a medição do nível da atividade radioativa $(\mu \mathrm{Sv} / \mathrm{h})$ presente na praia de Namorados variando no tempo, os estudos começaram em agosto de 2016 e foram até abril de 2017. Nesses nove meses de medidas, o intervalo entre as medidas foi de 21 dias.
Para a rota ser seguida várias vezes no mesmo caminho utilizamos as coordenadas de georreferenciamento da tabela a seguir.

Tabela 1: Coordenadas da rota utilizada.

\begin{tabular}{|l|l|}
\hline $20^{\circ} 49^{\prime} 39.60^{\prime \prime} \mathrm{S}$ & $40^{\circ} 41^{\prime} 23.67^{\prime \prime} \mathrm{W}$ \\
\hline $20^{\circ} 49^{\prime} 39.84 " \mathrm{~S}$ & $40^{\circ} 41^{\prime} 24.64^{\prime \prime} \mathrm{W}$ \\
\hline $20^{\circ} 49^{\prime} 40.40^{\prime \prime} \mathrm{S}$ & $40^{\circ} 41^{\prime} 25.47^{\prime \prime} \mathrm{W}$ \\
\hline $20^{\circ} 49^{\prime} 41.11^{\prime \prime} \mathrm{S}$ & $40^{\circ} 41^{\prime} 26.16^{\prime \prime} \mathrm{W}$ \\
\hline $20^{\circ} 49^{\prime} 41.83^{\prime \prime} \mathrm{S}$ & $40^{\circ} 41^{\prime} 26.89^{\prime \prime} \mathrm{W}$ \\
\hline $20^{\circ} 49^{\prime} 42.66 " \mathrm{~S}$ & $40^{\circ} 41^{\prime} 27.40^{\prime \prime} \mathrm{W}$ \\
\hline $20^{\circ} 49^{\prime} 43.55 " \mathrm{~S}$ & $40^{\circ} 41^{\prime} 27.72^{\prime \prime} \mathrm{W}$ \\
\hline $20^{\circ} 49^{\prime} 44.51^{\prime \prime} \mathrm{S}$ & $40^{\circ} 41^{\prime} 27.98^{\prime \prime} \mathrm{W}$ \\
\hline $20^{\circ} 49^{\prime} 45.477^{\prime \prime} \mathrm{S}$ & $40^{\circ} 41^{\prime} 27.95 " \mathrm{~W}$ \\
\hline $20^{\circ} 49^{\prime} 46.43 " \mathrm{~S}$ & $40^{\circ} 41^{\prime} 27.63^{\prime \prime} \mathrm{W}$ \\
\hline $20^{\circ} 49^{\prime} 47.16^{\prime \prime} \mathrm{S}$ & $40^{\circ} 41^{\prime} 26.92^{\prime \prime} \mathrm{W}$ \\
\hline
\end{tabular}




\section{Resultados e Discussões}

$\mathrm{Na}$ figura 01 , registramos as três primeiras medidas realizadas entre o mês de agosto de 2016 até abril de 2017 e obtivemos o seguinte gráfico.

Fig. 01. Gráfico das três primeiras medidas.

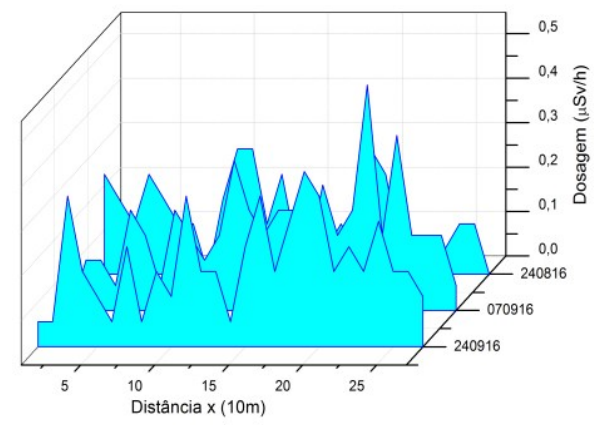

Á direita do gráfico acima temos 3 datas que foram feitas as medidas, a primeira foi feita em 24/08/16 a segunda em 07/09/16 e a terceira em 24/09/16.

Durante a primeira medida verificamos uma dose de aproximadamente $0,28(\mu \mathrm{Sv} / \mathrm{h})$ em três pontos, $100 \mathrm{~m}, 110 \mathrm{~m} \mathrm{e} 190 \mathrm{~m}$ na segunda medida verificamos uma dose de $0,50(\mu \mathrm{Sv} / \mathrm{h})$ em $210 \mathrm{~m}$, na terceira medida verificamos uma dosagem $0,39(\mu \mathrm{Sv} / \mathrm{h})$ em $190 \mathrm{~m}$.

Realizamos mais medidas e obtivemos o gráfico a seguir.

Fig. 02. Gráfico das três últimas medidas.

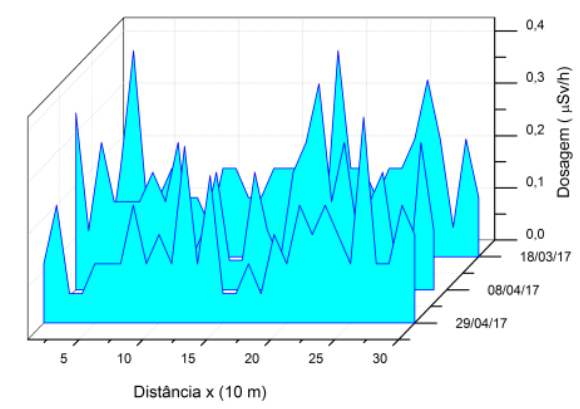

A medida do dia 18/03/17 mostra a dosagem de $0,39(\mu \mathrm{Sv} / \mathrm{h})$ em $30 \mathrm{~m}$ e $190 \mathrm{~m}$, na segunda medida verificamos uma dose de $0,39(\mu \mathrm{Sv} / \mathrm{h})$ em $200 \mathrm{~m}$, na terceira medida verificamos uma dosagem $0,39(\mu \mathrm{Sv} / \mathrm{h})$ próximo de $260 \mathrm{~m}$.

\section{Conclusões}

Nossas medições neste trabalho mostram que a radiação nesta praia varia de intensidade com o tempo e se desloca no espaço continuamente nesta praia, esta praia apresentou pouca intensidade de radiação.

O ponto a ser ressaltado aqui é de que análises instantâneas de amostras de areia não caracterizam bem a Praia de Namorados, uma vez que o sistema é dinâmico.

Somente uma análise temporal com base em 1 ano pode fornecer valores médios da atividade radioativa na Praia de Namorados.

\section{Referências}

[1] Orlando, M T D, et al. Correlation between Breast Cancer and Radiation Level of Guarapari City - ES, Blucher Proceedings ISSN: 2358-2359 V 01, (2014) n 02 DOI:10.5151/phypro-ecfa-020

[2] Fujinami, N.; T. Koga, T.; Morishima. H. External Expousure Rates From Terrestrial Radiantion At Guarapari And Meaipe In Brazil. (1999).

[3] Vasconcelos, D.C, Et Al. Modelling Natural Radioactivity In Sand Beaches Of Guarapari, Espírito Santo State, Brazil. (2013).

[4] Calheiro, D.S.; Passamai. Jr.,J.L. Estudo da Radiação na areia da Praia da Areia Preta. (2016). DOI: 10.5151/phypro-vii-efa-035

Agradecimentos.

Comissão Nacional de Energia Nuclear (CNEN), ao CNPQ e a Fundação de Amparo à Pesquisa e Inovação do Espírito Santo (FAPES) (projetos 098/2019 e 270/2019). 